Proceedings of XIX International Scientific Conference "New Technologies and Achievements in Metallurgy, Material Engineering, Production Engineering and Physics", Częstochowa, Poland, June 7-8, 2018

\title{
Welding and Characterization of Bulk Metallic Glasses Welds
}

\author{
W. PilarcZYK ${ }^{a, *}$, A. KAnia ${ }^{a}$ AND A. PilarCZYK ${ }^{b}$ \\ ${ }^{a}$ Silesian University of Technology, Faculty of Mechanical Engineering, Akademicka 2A, 44-100 Gliwice, Poland \\ ${ }^{b}$ Instytut Spawalnictwa, bł. Czesława 16-18, 44-100 Gliwice, Poland
}

\begin{abstract}
The main aim of this work is to present the structure and topography of the $\mathrm{Fe}_{37.44} \mathrm{Co}_{34.56} \mathrm{~B}_{19.2} \mathrm{Si}_{4.8} \mathrm{Nb}_{4}$ laser weld. A laser welding has been applied to increase the capability of using these materials in the industry. The amorphous and amorphous-crystalline phase were confirmed by X-ray analysis, atomic force microscopy, and high resolution transmission electron microscopy tests. The detailed topographic analysis revealed that the heat affected zone show a roughness characteristic of the crystalline phase and a smooth surface in the fusion zone.
\end{abstract}

DOI: $10.12693 /$ APhysPolA.135.249

PACS/topics: bulk metallic glasses, welding, triboindenter, surface topography, AFM, HRTEM

\section{Welding of amorphous materials}

Fe-based bulk metallic glasses (BMGs) attract the attention because of their good mechanical, physical properties, and sufficient glass forming ability (GFA). At present, it has been possible to weld BMG with various chemical compositions $(\mathrm{Pd}-\mathrm{Ni}-\mathrm{P}, \mathrm{Pd}-\mathrm{Cu}-\mathrm{Ni}-\mathrm{P}$, $\mathrm{Zr}-\mathrm{Ti}-\mathrm{Cu}-\mathrm{Ni}-\mathrm{Be}, \mathrm{Zr}-\mathrm{Al}-\mathrm{Cu}-\mathrm{Ni}$ ) using welding methods with the liquid phase content and in the supercooled liquid phase $[1,2]$.

The friction welding method was used during joining tests involving the supercooled liquid phase. In turn, welding tests involving the presence of the liquid phase were performed using electron beam welding, laser beam welding, explosion welding or electric welding $[3,4]$. The friction welding method was successfully used when joining palladium and zirconium-based amorphous alloys having the maximum glass transition temperature $\left(T_{g}\right)$ difference below $50 \mathrm{~K}$. In addition, the above-named alloys were joined with commercial aluminium alloys 2017 and 5083 [2], maintaining the amorphous structure and mechanical properties. Electron beam welding was successfully used when joining amorphous plates composed of $\mathrm{Zr}_{41} \mathrm{Ti}_{14} \mathrm{Cu}_{12} \mathrm{Ni}_{10} \mathrm{Be}_{23}$ and when joining plates composed of $\mathrm{Zr}_{41} \mathrm{Ti}_{14} \mathrm{Cu}_{12} \mathrm{Ni}_{10} \mathrm{Be}_{23}$ with crystalline alloy Zircaloy-4 and zirconium plates [2]. Welding with the liquid phase content is possible because of the high GFA of BMGs and the high concentration of welding energy [3]. In turn, the thermal stability and the superplasticity of the alloys enable the successful joining of BMGs in the supercooled liquid state [3].

Ultimately, the process of welding should ensure the continuity between welded elements as well as the homogeneity of the amorphous structure and properties in the welded joint area. The material continuity can be ensured by the proper making of imperfection-free welds. Research [5-8] revealed that the satisfaction of the

*corresponding author; e-mail: wirginia.pilarczyk@polsl.pl condition concerning structural, chemical and propertiesrelated homogeneity proves extremely difficult in terms of BMGs. The difference between the properties of the joint and those of the parent material (PM) indicates the quality of the welding process and is related to the notion of material weldability. The smaller the divergence between the structure and the properties of the PM and those of the joint, the better the weldability of a given material. The heat treatment of amorphous materials results not only in material heterogeneity but also in the generation of internal stresses, resulting from the nonuniform heating and cooling of joint elements during the process of welding. Depending on their intensity, internal stresses may trigger changes in shapes of welded joints or even lead to the formation of cracks.

When joining BMGs it is necessary to maintain their characteristic structure and properties. This can be achieved by the minimisation of the fusion zone (FZ) and the mutual exchange or evaporation of components of materials being welded, as well as through the reduction of joining time, aimed to prevent high temperatures from triggering the crystallisation of the amorphous structure. For this reason, it can be presumed that the ideal welding process should take place at the lowest possible temperature and at the shortest possible time. As a result, the most frequently applied methods are those which involve the use of sources characterised by high energy concentration, e.g. laser welding or electron beam welding [9, 10], as they enable the obtainment of appropriately high rates of heating and cooling in the weld [11]. Other commonly used methods include friction welding, explosion welding, and diffusion welding. Possible applications concerning the use of various welding techniques when joining selected BMGs are presented in works [2, 3, 12].

The main aim of this work is to present the structure and topography of the $\mathrm{Fe}_{37.44} \mathrm{Co}_{34.56} \mathrm{~B}_{19.2} \mathrm{Si}_{4.8} \mathrm{Nb}_{4}$ laser weld.

\section{Experimental procedure}

The tasted material was a $\mathrm{Fe}-\mathrm{Co}-\mathrm{B}-\mathrm{Si}-\mathrm{Nb}$ iron based alloy. The procedure for obtaining BMGs in the form 
of $1 \mathrm{~mm}$ in diameter plates involved the production of an ingot and then casting the metallic liquid into a copper mould. The test plates were prepared from pure elements, using an induction generator. The casting process of the liquid metal into a copper mould involved the melting in a quartz crucible using an induction generator and then raising the crucible plug and introducing the liquid into the mould with the argon gas pressure.

The amorphous and amorphous-crystalline phase were confirmed by X-ray analysis, high resolution transmission electron microscopy (HRTEM) and atomic force microscopy (AFM) tests.

The PANalytical XPERT PRO MPD X-ray diffractometer equipped with a $\mathrm{Cu}$ anode $\mathrm{X}$-ray tube was applied to identify the phase composition of the PM, FZ, and heat affected zone (HAZ). The operating parameters of the lamp were $30 \mathrm{~mA}$ and $40 \mathrm{kV}$. Diffraction patterns were performed in the angular range $2 \Theta$ from $10^{\circ}$ to $100^{\circ}$.

The HAZ and FZ observations were carried out using the Titan 80-300 transmission electron microscope of FEI firm.

For accurate surface structure analysis of welds, the Hysitron TI 950 Triboindenter equipped with QScope 250 microscopic attachement with Q-WM190 scanning probe was used.

\section{Characterization}

\section{of chosen bulk metallic glasses welds}

The X-ray diffraction analysis of Fe-based BMGs welds show that these materials have an amorphous and amorphous-nanocrystalline structure depending on the weld zone. The consolidation of image results and X-ray phase analysis enabled the structure characteristics in the individual weld zones. Figure 1 shows surface topography of FZ and HAZ boundaries of laser weld made by AFM. In Fig. 1d X-ray diffraction pattern was inserted.
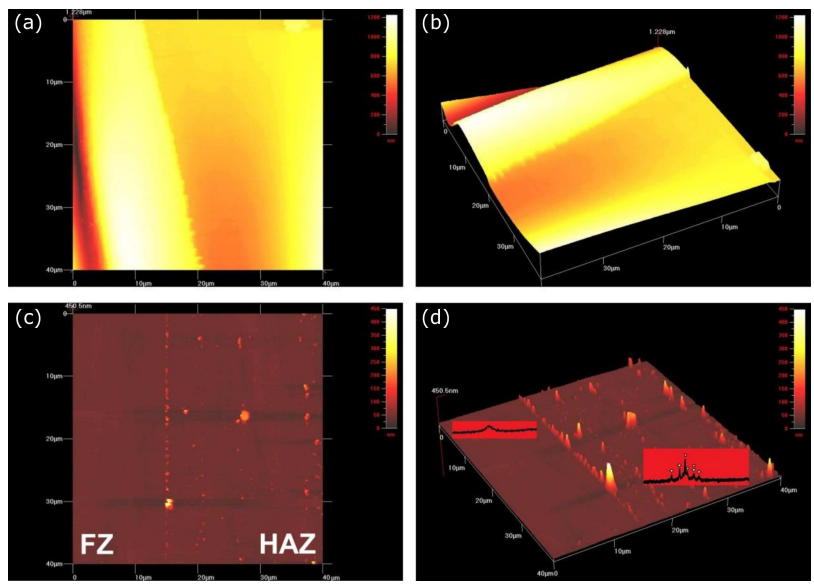

Fig. 1. Surface topography in the area of direct laser interaction (a), (b) and surface topography of boundary between FZ and HAZ of Fe-based BMGs laser weld (c) 2D image, (d) 3D image made by AFM with X-ray diffraction pattern.
The X-ray diffraction pattern of the $\mathrm{FZ}$ revealed wide, fuzzy spectra which are characteristic for amorphous structures, whereas, small diffraction lines from crystalline phases were observed in the X-ray diffraction pattern of the HAZ (Fig. 1d). This indicates an amorphouscrystalline structure in this zone. Diffraction analysis of the HAZ have shown the presence of lines which originated from the $(\mathrm{Fe}, \mathrm{Co}, \mathrm{Nb})_{23} \mathrm{~B}_{6}$ and $(\mathrm{Fe}, \mathrm{Co})_{3} \mathrm{~B}$ crystalline phases.

Crystallization in the HAZ may be caused by the oxidation of alloy elements $[13,14]$ which results in the reduction of the GFA or a prolonged influence of high temperature on this zone, as well as applying a high impulse energy of the laser beam.

The identification and the analysis of the welds were performed using HRTEM. Exemplary images of the amorphous and amorphous-nanocrystalline structure of selected areas are presented in Fig. 2 and Fig. 3.
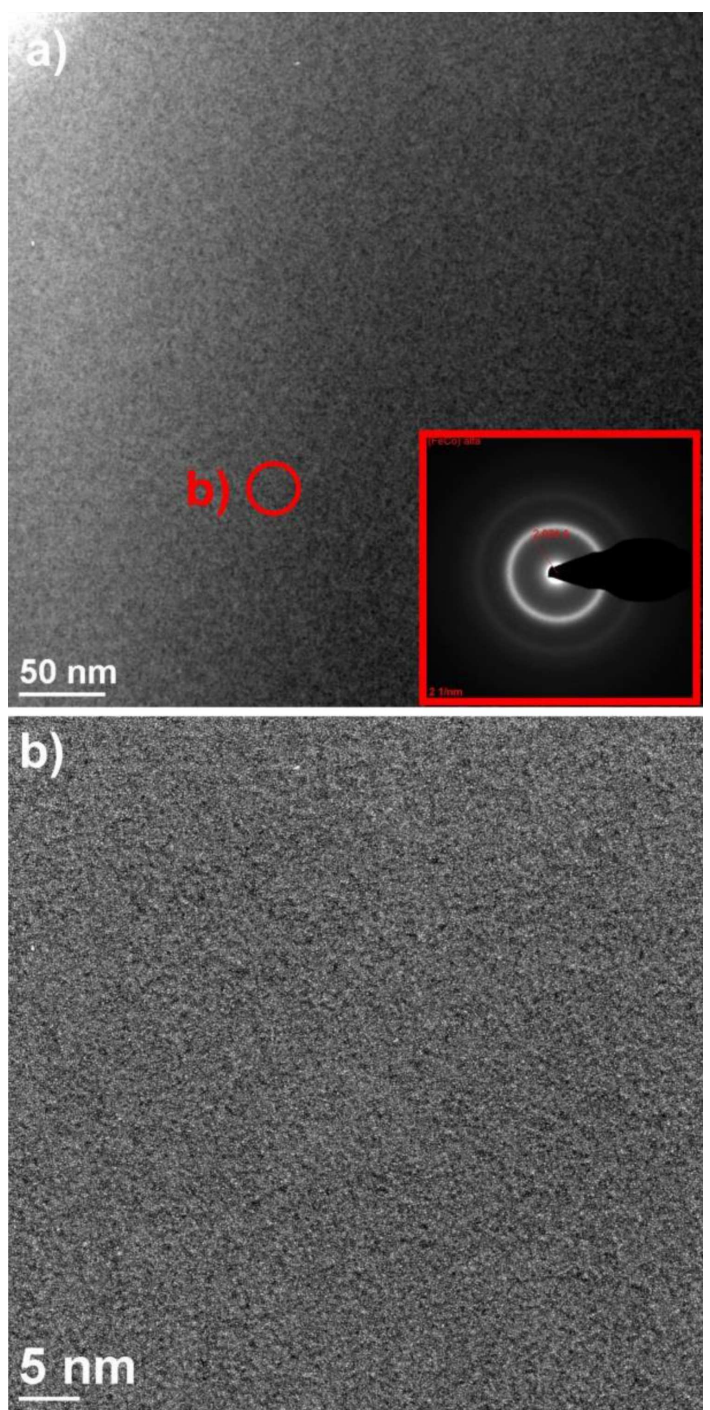

Fig. 2. Bright field image with selected area electron diffraction pattern for the amorphous plate in the FZ (a) and HRTEM image (b) from presented areas. 

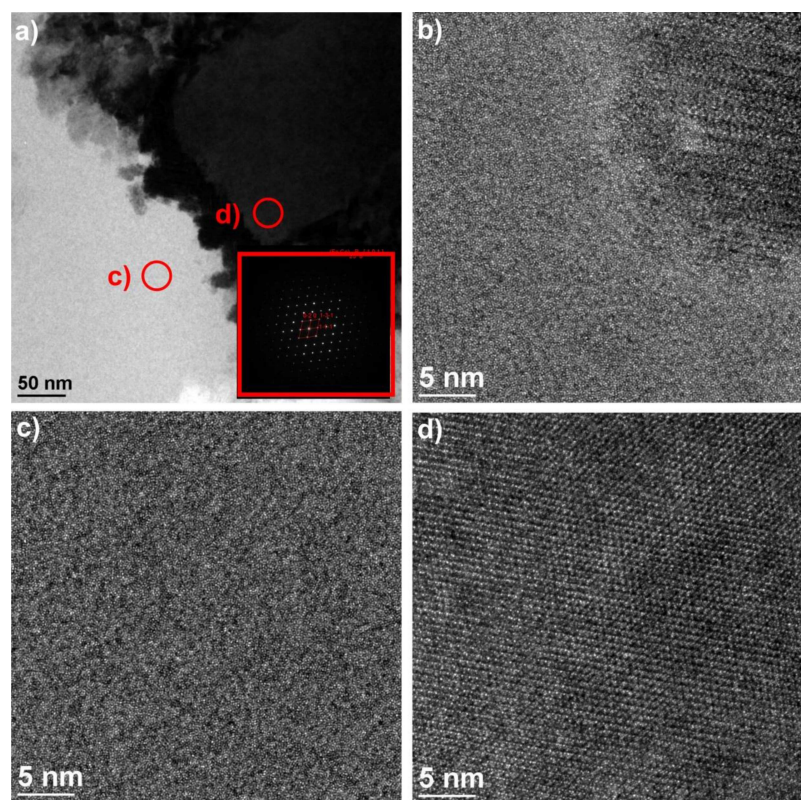

Fig. 3. Amorphous-crystalline structure image of HAZ of $\mathrm{Fe}-\mathrm{Co}-\mathrm{B}-\mathrm{Si}-\mathrm{Nb}$ bulk metallic glass weld and electron diffraction pattern from selected area (a), structure HRTEM images (b)-(d) from presented area.

The melting zone is smooth, without visible inequalities. The smooth surface of the FZ may suggest the presence of an amorphous phase. The surface texture is the result of the direct interaction of the high energy laser beam on the metastable material and rapid cooling of the metallic liquid. The fusion zone surface is without visible roughness. The surface topography in the zone between the FZ and HAZ shows a distinctive roughness which reflect the presence of crystallites.

\section{Conclusions}

The amorphous structure in FZ has been confirmed by XRD, AFM, and HRTEM analysis. The inequalities are located in the HAZ which confirms the occurrence of the crystalline phase. The XRD patterns of the HAZ revealed wide and diffuse spectra characteristic of the amorphous structure and the $(\mathrm{Fe}, \mathrm{Co}, \mathrm{Nb})_{23} \mathrm{~B}_{6}$ and $(\mathrm{Fe}$, $\mathrm{Co})_{3} \mathrm{~B}$ crystalline phase-related thin diffraction lines.

\section{Acknowledgments}

This work presentation was supported by National Science Centre (NCN) (project no. 2011/01/D/ ST8/07327).

This publication was financed by the Ministry of Science and Higher Education of Poland as the statutory financial grant of the Faculty of Mechanical Engineering SUT.

\section{References}

[1] G. Wang, Y.J. Huang, M. Shagiev, J. Shen, Mater. Sci. Eng. A 541, 33 (2012).

[2] Y. Kawamura, T. Shoji, Y. Ohno, J. Non-Cryst. Solids 317, 152 (2003).

[3] Y. Kawamura, Mater. Sci. Eng. A 375-377, 112 (2004).

[4] H.H. Yan, Y.D. Qu, X.J. Li, Combustion, Explosion, and Shock Waves 44, 491 (2008).

[5] H.S. Wang, H.G. Chen, J.S.C. Jang, J. Alloys Comp. 495, 224 (2010).

[6] W. Pilarczyk, Appl. Surf. Sci. 374, 359 (2016).

[7] W. Pilarczyk, Cryst. Res. Technol. 50, 700 (2015).

[8] W. Pilarczyk, O. Starczewska, D. Łukowiec, Phys. Status Solidi B 252, 2598 (2015).

[9] PN-EN ISO 15609-3:2007, Specification and qualification of welding procedures for metallic materials Welding procedure specification - Part 3: Electron beam welding.

[10] PN-EN ISO 15609-4:2009, Specification and qualification of welding procedures for metallic materials - Welding procedure specification - Part 4: Laser beam welding.

[11] J. Kim, D. Lee, S. Shin, C. Lee, Mater. Sci. Eng. A 434, 194 (2006).

[12] P.H. Kuo, S.H. Wang, P.K. Liaw, G.J. Fan, H.T. Tsang, D. Qiao, F. Jiang, Mater. Chem. Phys. 120, 532 (2010).

[13] T. Lipiński, Arch. Metall. Mater. 60, 3B, 321 (2015).

[14] A. Kupczyk, J. Świerczek, M. Hasiak, K. Prusik, J. Zbroszczyk, P. Gębara, J. Alloys Comp. 735, 253 (2018). 